\author{
Igor Sukhotnik - Arnold G. Coran - Alexander Kramer \\ Eitan Shiloni · Jorge G. Mogilner
}

\title{
Advances in short bowel syndrome: an updated review
}

Accepted: 7 July 2005 / Published online: 3 November 2005

(C) Springer-Verlag 2005

\begin{abstract}
Short bowel syndrome (SBS) continues to be an important clinical problem due to its high mortality and morbidity as well as its devastating socioeconomic effects. The past 3 years have witnessed many advances in the investigation of this condition, with the aim of elucidating the cellular and molecular mechanisms of intestinal adaptation. Such information may provide opportunities to exploit various factors that act as growth agents for the remaining bowel mucosa and may suggest new therapeutic strategies to maintain gut integrity, eliminate dependence on total parenteral nutrition, and avoid the need for intestinal transplantation. This review summarizes current research on SBS over the last few years.
\end{abstract}

Keywords Intestine Adaptation - Short bowel syndrome $\cdot$ Research $\cdot$ Intestinal growth

I. Sukhotnik $(\bowtie) \cdot$ J. G. Mogilner

Department of Pediatric Surgery B, Bnai Zion Medical Center, 47 Golomb Street, P.O.B. 4940, Haifa, 31048 Israel

E-mail: igor-dr@internet-zahav.net

E-mail: olguer@bezeqint.net

Tel.: + 972-4-8359647

Fax: +972-4-8359620

A. G. Coran

Carmel Medical Center, Rappaport Faculty of Medicine,

The Technion, Haifa, Israel

A. G. Coran

Section of Pediatric Surgery, C.S. Mott Children's Hospital, University of Michigan Medical School, Ann Arbor, MI, USA

E-mail: acoran@umich.edu

\section{A. Kramer · E. Shiloni}

Department of General Surgery, Carmel Medical Center, Rappaport Faculty of Medicine, The Technion, Haifa, Israel

E-mail: yuvalkra@zahav.net

E-mail: shil@netvision.net.il

\section{Introduction}

Short bowel syndrome (SBS) is defined as intestinal failure following the loss of intestinal length or competence below the minimal amount necessary for the absorption of nutrients to maintain a normal nutritional status [1-3]. SBS typically follows resection of $50 \%$ or more of the small intestine and is associated with diarrhea, steatorrhea, dehydration, electrolyte disturbances, malabsorption and progressive malnutrition $[2,3]$. SBS is a common problem in pediatric surgery and occurs in newborns and infants suffering from necrotizing enterocolitis, intestinal atresia and volvulus requiring massive intestinal resection. In adults, Crohn's disease, radiation enteritis, massive resections due to catastrophic mesenteric vascular events, intestinal obstruction, and trauma represent the more common causes of SBS [4]. SBS remains a significant cause of infant morbidity and mortality despite the availability of total parenteral nutrition (TPN), advances in resuscitation, availability of potent antibiotics, and modern techniques of organ support [5].

The key to survival after massive small bowel resection is the ability of the residual intestine to adapt. In this setting, adaptation means progressive recovery from intestinal failure throughout which the small bowel increases its absorptive surface area and its functional capacity in an attempt to meet the body's metabolic and growth needs [6]. Intestinal adaptation constitutes the best option for patients with SBS. In humans, intestinal adaptation begins within $24-48 \mathrm{~h}$ of resection and includes morphologic (structural adaptation) and functional changes (functional adaptation) of the residual bowel. Structural adaptation includes increasing bowel diameter and length, lengthening the villi, deepening the crypts, and increasing the rate of enterocyte proliferation, finally resulting in increased absorptive surface area and an increased numbers of enterocytes. Functional adaptation entails modifications of the brush border membrane permeability and upregulation of 
carrier-mediated transport, ultimately resulting in increased nutrient absorption by isolated enterocytes. The dynamic process of enterocyte turnover is a function of the rates of crypt cell proliferation, migration along the crypt-villus axis, proliferation, and death via apoptosis. This process may be affected by nutritional status, the route of feeding, and the adequacy of specific nutrients in the diet. Apoptosis or programmed cell death is an active, genetically controlled process of cell suicide. It is a physiologic process whereby the body disposes of unwanted cells by self-destruction and is our greatest defense against damaged cells [7]. In contrast to necrosis, which is more of an accidental death process, apoptosis comprises highly regulated and reproducible events that eventually lead to cell death. Several regulatory genes affecting apoptosis have been identified and divided into pro-apoptotic genes (bax, bik, bak, bcl-xs, bad, p53, cjun, hrk) and anti-apoptotic genes (bcl-2, bcl- $x_{L}, \mathrm{rb}, \mathrm{mcl}-$ 1, a1, brag-1, bfl-1) [8]. Recent evidence has demonstrated that apoptosis increases in SBS [9]. Enhanced enterocyte apoptosis following bowel resection is a mechanism which counterbalances the increased enterocyte proliferation in order to reach a new homeostatic status during intestinal adaptation and which promotes the disposal of genetically aberrant stem cells and prevents tumorigenesis (9). In a recent experiment, Jarboe et al. [10] examined the role of bax in exaggerated postresection apoptosis induced by epidermal growth factor receptor inhibition in a mouse and demonstrated that bax is required for the induction of such cell death. Moreover, defective epidermal growth factor receptor signaling augmented resection-induced enterocyte apoptosis via a mechanism that also requires bax expression.

Identification of factors that promote growth and regeneration of the intestinal epithelium and reduce apoptosis may suggest new therapeutic strategies for maintaining gut integrity following massive small bowel resection. Not all investigators, however, support this concept. Juno et al. [11] recently examined mucosal growth after small bowel resection in bax-null and corresponding wild-type (WT) mice. They had expected increased enterocyte apoptosis after bowel resection in the WT mice and unchanged apoptosis in the bax-null mice but all parameters of adaptation and proliferation increased equally after bowel resection in both groups of mice. The authors concluded that while bax deficiency prevents an increase in enterocyte apoptosis after bowel resection, attenuation of postresection enterocyte apoptosis does not augment mucosal adaptation to massive intestinal loss [11].

\section{Enhancing intestinal adaptation}

Although intestinal transplantation (IT) has emerged as a feasible alternative in the treatment of children with SBS during the last two decades, intestinal adaptation remains the only chance for survival in a subset of these patients. Considerable research over many years has focused on the identification of those trophic factors that may promote bowel absorption after massive intestinal resection and provide a successful outcome in patients with SBS. These factors include nutrients and other luminal constituents, gastrointestinal secretions, hormones and peptide growth factors $[2,3,6]$.

\section{Adaptation and nutrients}

The initial management of patients with SBS typically involves TPN. TPN is usually initiated as soon as clinical stability allows, and provides adequate total caloric intake and the necessary amounts of nutrients and micronutrients. Importantly, it also "buys time" for gradual tolerance of enteral feedings and successful adaptation of the intestine. Early gradual introduction of enteral feedings also plays an important role in successful postoperative management. It is well documented that exposure to intraluminal nutrients is required for the stimulation of intestinal adaptation in general and in mucosal hyperplasia in particular [2, 12]. Therefore, many experts in the management of SBS recommend attempting enteral feeding as early as possible [2]. The mechanism whereby food induces this adaptation is unknown. It is likely that enteral nutrition works through a number of smechanisms, including stimulation of mucosal hyperplasia by direct contact with the epithelial cells, stimulation of trophic gastrointestinal hormone secretion and stimulation of the production of trophic pancreaticobiliary secretions [13]. Although enteral feeding is one of the major trophic factors in the stimulation of intestinal adaptation, not all nutrients have equal stimulating trophic effects. Long chain fatty acids (LCFAs) are considered the most effective among the factors promoting postresection intestinal adaptation [2]. Although there is a decreased ability to absorb many nutrients following resection, lipid absorption is generally considered the most vulnerable. The combined loss of absorptive surface area and compromised enterohepatic circulation, decreased bile acid pool and relative pancreatic insufficiency result in inefficient absorption of fat and subsequent steatorrhea. Therefore, patients with SBS have been considered to benefit from a low fat diet early in the course of therapy [14]. It has been shown, however, that LCFAs appear to be more effective stimulators of intestinal adaptation than either medium-chain fats or carbohydrates [15]. Our group recently showed that early exposure to a high-fat diet augmented and accelerated intestinal regrowth after massive small bowel resection in a rat [16]. In addition, dietary lipids increased the absorptive capacity of the intestinal remnant, improved food and fat absorption, and restored plasma and tissue lipid content in this model [17]. In contrast, a low-fat diet significantly inhibited postresection intestinal regrowth. In an earlier study [18], we demonstrated that exposure to a low-fat diet following small bowel resection in rats inhibited all 
parameters of intestinal adaptation (bowel and mucosal weight, mucosal DNA and protein, villus height and crypt depth, and rate of enterocyte proliferation). A lowfat diet affected adaptive responses by an inhibition of enterocyte proliferation and did so independent of enterocyte apoptosis [18]. In another investigation [19], we reported that depletion of dietary fat inhibited cellular and molecular mechanisms of LCFA absorption by isolated enterocytes in the same model. This was associated with a decrease in LCFA plasma-membrane transport protein fatty-acid translocase (FAT) (the rat homologue of human CD36) and with a decrease in isolated enterocyte $[3 \mathrm{H}]$-oleate uptake as measured by an established cellular LCFA transport assay [19].

Extensive studies in various experimental models of SBS have established that many amino acids (for example, glutamine) strongly stimulate the intestinal adaptive response. Arginine is a dibasic non-essential amino acid processed metabolically by the urea cycle. It plays an important role in many physiologic and biologic processes beyond its role as a protein-incorporated amino acid. Dietary supplementation with arginine has been shown to enhance wound healing, regulate endocrine activity and potentiate immune activity. Arginine has attracted much interest over the past two decades after having been identified as the natural substrate of nitric oxide, and is now recognized as playing a major role in many regulation processes. We recently investigated the effects of oral arginine on intestinal regrowth following massive small bowel resection in a rat. Our findings showed that oral arginine impairs postresection intestinal regrowth in rats through a decrease in enterocyte proliferation and an increase in cell death via apoptosis [20]. This effect was the opposite of the positive gut trophic effects of arginine reported in many gastrointestinal disorders, such as intestinal ischemiareperfusion injury, ulcerative ileitis, and radiation enteritis [21]. We hypothesized that the effects of arginine and nitric oxide on enterocyte proliferation and apoptosis may be different in proliferating and nonproliferating intestinal mucosa.

Vitamin A is essential for normal growth and for differentiation of epithelial tissues. Extensive studies in various experimental models have established that vitamin A may regulate intestinal epithelial cell proliferation and regeneration. Swartz-Basile et al. [22] examined the mechanisms by which the status of vitamin A affects adaptation by analyzing proliferation, apoptosis, and enterocyte migration in the early postoperative period after bowel resection in the rat. Both crypt cell proliferation and enterocyte migration rates were significantly decreased in the vitamin A-deficient rats subjected to submassive small bowel resection. In contrast, apoptosis was significantly greater in the remnant ileum of resected vitamin A-deficient rats compared to control animals. The authors concluded that vitamin A deficiency inhibits intestinal adaptation following partial small bowel resection by reducing crypt cell proliferation, by enhancing early crypt cell apoptosis, and by markedly reducing enterocyte migration rates [22].

\section{Intestinal adaptation and hormones}

It is widely accepted that the adaptive response is controlled in part by the release of one or more of the gut signaling hormones. These include enteroglucagon, neurotensin, peptide YY, growth hormone, and insulin like growth factor [23]. Additionally, enteral feeding stimulates the release of enterotrophic hormones (gastrin, cholecystokinin, neurotensin) which have an important role in the process of gut adaptation. There is growing evidence in animal models of SBS that some hormonal manipulation can improve intestinal adaptation.

Extensive studies in various experimental models of SBS have established that exogenous administration of growth hormone enhances mucosal hyperplasia and increases water, electrolyte and nutrient absorption [24, 25]. In a rabbit model of SBS, Avissar et al. [26] recently demonstrated that treatment with growth hormone for 2 weeks restored a $\mathrm{Na}(+)$-dependent broad-spectrum neutral amino acid transporter $(\mathrm{ATB}(0) / \mathrm{ASCT} 2)$ protein in the jejunum and ileum, which is responsible for downregulated glutamine transport in rabbit residual bowel following 70\% small bowel resection [26].

Since Wilmore et al.'s [27]demonstration that a combination of growth hormone, glutamine and a specialized diet enhanced intestinal compensation and optimized nutrient absorption in patients with intestinal failure, many similar studies have been conducted with inconsistent results. For example, Matarese et al. performed a systematic search of electronic databases and the Internet for the purpose of compiling the evidence published to date on this subject. The authors concluded that the administration of recombinant human growth hormone alone or together with glutamine with or without a modified diet may be beneficial when the appropriate patients are selected for treatment [28].

We recently studied the effect of gender and sex hormones on intestinal adaptation in a rat model of SBS and showed that bowel regrowth following massive small bowel resection in the rat was not gender related. A depletion of androgens by castration in male rats, however, did inhibit intestinal adaptation while, in contrast, treatment with exogenous testosterone appeared to strongly stimulate intestinal regrowth following bowel resection in male rats [29].

Enteroendocrine glucagon-like peptides GLP-1 and GLP-2 are synthesized and released from enteroendocrine cells in the distal small intestine and large intestine. GLP-1 promotes efficient nutrient assimilation while GLP-2 regulates energy absorption via effects on nutrient intake, gastric acid secretion, gastric emptying, nutrient absorption and mucosal permeability [30]. Evidence that GLP-2 is important in controlling intestinal adaptation following bowel resection has come 
from experiments by Litvak et al. [31]. In addition, Martin et al. [32] have recently shown that luminal nutrients stimulate bowel growth and differentiation by stimulation of GLP-2 secretion, and that GLP-2 levels significantly correlated with the magnitude of intestinal resection and nutrient malabsorption. Uluutku et al. [33] investigated the trophic and functional effects of bombesin on remaining gut in rats with SBS and showed an increased absorptive capacity and improved serum protein and albumin levels following bombesin administration, even in the absence of elemental nutrition.

Because of its antisecretory properties, somatostatin has been advocated for the treatment of patients with SBS. Somatostatin decreases diarrhea and stoma output following massive small bowel resection. We examined the effect of Sandostatin (octreotide acetate) on structural intestinal adaptation, cell proliferation and apoptosis in a rat model of SBS [34]. Sandostatin decreased cell proliferation and inhibited structural intestinal adaptation following massive small bowel resection in the rat. In light of these results, we consider that somatostatin should be avoided following massive small bowel resection in order to prevent its inhibitory effects on bowel regrowth.

\section{Adaptation and peptide growth factors}

The investigation of peptide growth factors has been one of the most exciting areas of gastroenterological research in the past four decades. Peptide growth factors are divided into several families based on their structure and mechanisms of action. They include the epidermal growth factor (EGF) family, the transforming growth factor $\beta$ (TGF $\beta)$ family, the insulin-like growth factor (IGF) family, the fibroblast growth factor (FGF) family, keratinocyte growth factor (KGF), glucagon-like peptide-2 (GLP-2), hepatocyte growth factor (HGF), platelet-derived growth factor (PDGF), trefoil peptides, hematopoietic stem cell factor, and others.

Transforming growth factor-alpha (TGF- $\alpha$ ) is a $5.5 \mathrm{kDa}$ protein containing 50 amino acid residues that share 35\% structural homology with EGF, a common membrane receptor with a similar spectrum of biological activity. We demonstrated that exogenous TGF- $\alpha$ clearly accelerates intestinal re-growth following bowel resection in the rat [35], and showed that both increased cell production and decreased cell death via apoptosis were responsible for this positive effect.

The IGF system was discovered as a group of factors in serum that mediate the growth-promoting effects of growth hormone on the skeleton [36]. This system includes the ligands IGF-I and IGF-II, the receptors IGFRs type 1 and type 2, and six high-affinity bindings proteins (IGFBPs 1-6) that modulate IGF cellular actions [37]. The role of the IGF system in growth and differentiation of bowel during development has been reported by many investigators $[38,39]$, and systemic or local IGF-I administration has been shown to enhance bowel regrowth and improve nutrient absorption in many animal models of SBS [40, 41]. Although a positive effect of IGF-I in SBS has been reported by many investigators, little evidence exists to indicate that insulin may affect intestinal growth following bowel resection. The results of our recently completed study [42] have shown that subcutaneous insulin moderately simulated intestinal mucosal regrowth in jejunum and ileum after a $75 \%$ small bowel resection in a rat model of SBS. At the same time, oral insulin dramatically enhanced structural intestinal adaptation in ileum and had a less significant stimulation effect in jejunum compared to subcutaneous insulin.

$\mathrm{KGF}$ is a form of an endogenous epithelial tissue growth factor that stimulates the growth of cells on the surface of the gastrointestinal tract. Yang et al. [43] have recently demonstrated that intraepithelial lymphocyte (IEL)-derived KGF promotes intestinal epithelial cell proliferation and increases villus growth in a mouse model of SBS. KGF expression was highest in the crypts, and decreased progressively in the lower and upper portion of the villi. SBS was associated with an upregulation of IEL-derived KGF expression, while TPN administration was associated with a downregulation of IEL-derived KGF expression.

\section{SBS and sepsis}

Sepsis is a leading cause of death in patients suffering from SBS. The majority of the septic episodes occur in patients who receive TPN and are mostly related to the catheter. The role of bacterial overgrowth with subsequent bacterial translocation (BT) has also been described at length. Asensio et al. investigated BT after four different types of gut resection in rats that were fed orally or received TPN. Their results showed that both small bowel resection and TPN were associated with increased BT. Interestingly, the extent of BT in this experiment decreased after resection of the ileo-cecal valve [44]. O'Brien et al. [45] examined intestinal permeability and BT in the adapting remnant ileum after massive small bowel resection in mice. Intestinal permeability to macromolecules was shown not to have increased after massive bowel resection, but the rate of translocation to the mesenteric lymph nodes and liver was elevated. The authors concluded that the mechanism for BT after bowel resection was not related to gut permeability.

A complex of several immunologic and nonimmunologic factors maintains the barrier function of the gastrointestinal tract. The immune system of the intestine includes Peyer's patches, lymphoid cells located within the intestinal lamina propria, intraepithelial lymphocytes (IEL) and aggregated lymphoid tissue within mesenteric lymph nodes. In a recent experiment, Wildhaber et al. [46] investigated gene alteration of IEL following small bowel resection in mice and showed that IEL undergo temporal changes after bowel resection. The authors concluded that these observations provide 
profound insight into potential IEL-dependent regulation of enterocyte homeostasis in addition to their role in gut barrier function in SBS.

Although sepsis is commonly associated with or complicates SBS, endotoxemia itself may affect intestinal regrowth after bowel resection. We investigated the effect of lipopolysaccharide endotoxemia on intestinal adaptation in a rat model of SBS [47]. Our results established that endotoxemia inhibits structural intestinal adaptation and increases mortality following massive small bowel resection in rats .

\section{Hepatic failure and SBS}

Liver disease is the second (after sepsis) most significant risk factor for morbidity and mortality in patients with SBS. Abnormal liver function occurs in $30-60 \%$ of patients who underwent massive small bowel resections and is one of the main reasons for long-term use of TPN, for underlying disease necessitating TPN for adequate nutrition, and for the gastrointestinal dysfunction associated with the absence of enteric nutrients while receiving TPN [48]. TPN-related liver disease is usually related to intrahepatic cholestasis in children and to steatosis in adults. Long-term TPN is frequently complicated by a syndrome of progressive cholestatic liver disease that is considered to be irreversible beyond the early stages of cholestasis, particularly in the presence of any degree of fibrosis in the liver. About $3-19 \%$ of children with SBS eventually develop hepatic failure and require liver transplantation. Multifactorial theories on the origin of parenteral nutrition-associated cholestasis have not yet succeeded in defining its pathogenesis nor have they resulted in a solution to the problem. Identification of those factors that improve hepatocyte secretion and bile formation and flow will pave the way for new therapeutic strategies to improve overall survival of patients with SBS.

Quiros-Tejeira et al. [49] analyzed the outcome of 78 children with SBS who required long-term parenteral nutrition. The authors showed that TPN-associated early persistent cholestatic jaundice as well as small bowel length (i.e., $<15 \mathrm{~cm}$ ) were linked with a higher mortality rate. Weber and Keller [50] examined the effects of liver dysfunction and portal hypertension on intestinal adaptation in 42 infants with SBS. They demonstrated that time to feeding tolerance increased significantly with advanced liver disease (Child's classification) and concluded that cholestatic liver disease, especially when associated with portal hypertension, adversely affects bowel adaptation in SBS.

\section{SBS and transplantation}

The surgical treatment of SBS has been traditionally based on the correction of mechanical obstruction, which is responsible for bacterial overgrowth on increase in intestinal absorptive surface area and on slowing of intestinal transit. Since the introduction of clinical IT by Lillehei in 1964 [51], IT and multivisceral transplantation have become the clinical challenge of the new millennium. Research is now focused upon improvement in the technique of transplantation, in the identification of the immunosuppressive regimens to control rejection and in the postoperative monitoring and critical care of the recipient.

The indications and timing of IT are still controversial. In a recent clinical trial, Atalay et al. [52] tried to evaluate the indications for IT and concluded that stable patients with a very short bowel are suitable candidates for IT. However, when the colon is intact, regardless of small bowel remnant length, the patient should be given a chance to develop intestinal adaptation before making the decision for an IT.

Rescue with tissue-engineered small intestine after massive small bowel resection in rats was recently described [53]. Anastomosis of this material significantly improved the animals' postoperative weight and B12 absorption after bowel resection. Gunsar et al. [54] examined the growth ability of intestinal neomucosa on a serosal surface in order to assess its histologic maturity in a rat with SBS; neomucosa showed histologic maturity and structural similarity with the native small bowel mucosa after eight weeks of growth.

Small intestinal submucosa has been considered for use as an extracellular matrix in tissue engineering. Wang et al. [55] recently interposed a 2-cm length of tubular small intestinal submucosa graft from donor rats with a bilateral anastomosis in the middle of an isolated ileal loop, and documented a rapid regeneration of mucosa and smooth muscle in the graft. The authors concluded that a small intestinal submucosa graft might be a viable material for the creation of neointestine.

\section{Clinical trials in SBS}

Although extensive studies in various experimental models of SBS have identified a variety of factors that promote intestinal proliferation and nutrient absorption, only a few clinical trials have focused on the effects of these factors on intestinal growth in humans. McDoniel et al. [56] evaluated the use of clonidine (alpha2adrenergic receptor agonist) in two patients with SBS and high intestinal outputs who were refractory to conventional therapy with antidiarrheal and antisecretory agents. They showed that oral clonidine, $0.1 \mathrm{mg}$ twice daily, decreased one patient's ostomy output from approximately $4 \mathrm{l}$ /day to approximately $1 \mathrm{l}$ /day, eliminated the need for parenteral nutrition and intravenous fluids and decreased the need for opiate therapy. The addition of oral clonidine, $0.2 \mathrm{mg}$ twice daily, in the second patient resulted in decreased rectal outputs from approximately $4 \mathrm{l}$ /day to approximately $1.5 \mathrm{l}$ /day. Kato et al. [57] recently demonstrated that parenteral cimetidine significantly decreased stool fluid excretion, urine 
output and electrolyte loss following massive small bowel resection in patients with gastrointestinal cancer. Seguy et al. [58] assessed treatment with low-dose of growth hormone for 3 weeks in 12 adult patients with SBS. The treatment increased intestinal absorption of calories, nitrogen, carbohydrates, and fat and was associated with increased body weight, lean body mass, D-xylose absorption, insulin-like growth factor 1 and insulin-like growth factor binding protein in plasma. The authors concluded that three weeks of low-dose growth hormone significantly improved intestinal absorption in TPN-dependent SBS patients who were on a hyperphagic western diet.

Despite vast recent advances in our understanding of the pathophysiology of SBS and of the cellular and molecular mechanisms of intestinal adaptation following massive small bowel resection, more questions have been raised than answered. Additional studies should be performed to determine the molecular and cellular mechanisms of nutrient absorption following the administration of different proadaptive factors, to define the mechanisms of cell proliferation and apoptosis during intestinal adaptation, to identify new factors that stimulate bowel regrowth after bowel resection, and to determine basic mechanisms of nutrient growth factor interaction and the clinical efficacy of combinations of different factors. Further advances in the research of SBS may well be lifesaving for many infants, children and adults facing massive small bowel loss who would not have survived in the past. These advances also represent major challenges in decreasing morbidity and in improving our care of these patients and their families.

Acknowledgements Esther Eshkol is thanked for editorial assistance.

\section{References}

1. Sigalet DL (2001) Short bowel syndrome in infants and children: an overview. Semin Pediatr Surg 10:49-55

2. Vanderhoof JA (1996) Short bowel syndrome. Neonat Gastroenterol 23:377-386

3. Booth IW, Lander AD (1998) Short bowel syndrome. Bailliere's Clin Gastroenterol 12:739-772

4. DiBaise JK, Young RJ, Vanderhoof JA (2004) Intestinal rehabilitation and the short bowel syndrome. Am J Gastroenterol 99:1386-1395

5. Coran AG, Spivak D, Teitelbaum DH (1999) An analysis of the morbidity and mortality of short bowel syndrome in the pediatric age group. Eur J Pediatr Surg 9:228-230

6. O'Brien DP, Nelson LA, Huang FS, Warner BW (2001) Intestinal adaptation: structure, function, and regulation. Semin Pediatr Surg 10:56-64

7. Kerr JF, Wyllie AH, Currie AR (1972) Apoptosis: a basic biological phenomenon with wide-ranging implications in tissue kinetics. Br J Cancer 26:239-257

8. Fan XQ, Guo YJ (2001) Apoptosis in oncology. Cell Res 11:1-

9. Que FG, Gores GJ (1996) Cell death by apoptosis: basic concepts and disease relevance for the gastroenterologist. Gastroenterology 110:1238-1243
10. Jarboe MD, Juno RJ, Bernal NP, Knott AW, Zhang Y, Erwin CR, Warner BW (2004) Bax deficiency rescues resection-induced enterocyte apoptosis in mice with perturbed EGF receptor function. Surgery 136:121-126

11. Juno RJ, Knott AW, Profitt SA, Jarboe MD, Zhang Y, Erwin CR, Warner BW (2004) Preventing enterocyte apoptosis after massive small bowel resection does not enhance adaptation of the intestinal mucosa. J Pediatr Surg 39:907-911

12. Levine GM, Deren JJ, Yezdimir E (1976) Small bowel resection: oral intake is the stimulus for hyperplasia. Am J Dig Dis 21:542-546

13. Lentze MJ (1989) Intestinal adaptation in short-bowel syndrome. Eur J Pediatr 148:294-299

14. Menge H, Grafe M, Lorenz-Meyer H, Riecken EO (1975) The influence of food intake on the development of structural and functional adaptation following ileal resection in the rat. Gut $16: 468-472$

15. Park JHY, Grandjean CJ, Hart MH, Vanderhoof JA (1989) Effects of dietary linoleic acid on mucosal adaptation after small bowel resection. Digestion 44:57-65

16. Sukhotnik I, Mor-Vaknin N, Drongowski RA, Miselevich I, Coran AG, Harmon CM (2004) Effect of dietary fat on early morphological intestinal adaptation in a rat with short bowel syndrome. Pediatr Surg Int 20:419-424

17. Sukhotnik I, Mor-Vaknin N, Drongowski RA, Coran AG, Harmon CM (2004) Effect of dietary fat on fat absorption and concomitant plasma and tissue fat composition in a rat model of short bowel syndrome. Pediatr Surg Int 20:185191

18. Sukhotnik I, Shiloni E, Krausz MM, Yakirevich E, Sabo E, Mogilner J, Coran AG, Harmon CM (2003) Low-fat diet impairs postresection intestinal adaptation in a rat model of short bowel syndrome. J Pediatr Surg 38:1182-1187

19. Sukhotnik I, Gork AS, Chen M, Drongowski RA, Coran AG, Harmon CM (2001) Effect of low fat diet on lipid absorption and fatty-acid transport following bowel resection. Pediatr Surg Int 17:259-264

20. Sukhotnik I, Lerner A, Sabo E, Krausz MM, Siplovich L, Coran AG, Mogilner J, Shiloni E (2003) Effects of enteral arginine supplementation on the structural intestinal adaptation in a rat model of short bowel syndrome. Dig Dis Sci 48:1346-1351

21. Kirk SJ, Barbul A (1990) Role of arginine in trauma, sepsis and immunity. JPEN 14(5 suppl):226S-229S

22. Swartz-Basile DA, Wang L, Tang Y, Pitt HA, Rubin DC, Levin MS (2003) Vitamin A deficiency inhibits intestinal adaptation by modulating apoptosis, proliferation, and enterocyte migration. Am J Physiol Gastrointest Liver Physiol 285:G424-G432

23. Nightingale JM, Kamm MA, van der Sijp JR, Ghatei MA, Bloom SR, Lennard-Jones JE (1996) Gastrointestinal hormones in short bowel syndrome. Peptide YY may be the 'colonic brake' to gastric emptying. Gut 39:267-272

24. Shulman DI, Hu CS, Duckett G, Lavallee-Grey M (1992) Effects of short-term growth hormone therapy in rats undergoing $75 \%$ small intestinal resection. J Pediatr Gastroenterol Nutr $14: 3-11$

25. Mainoya JR (1982) Influence of bovine growth hormone on water and $\mathrm{NaCl}$ absorption by the rat proximal jejunum and distal ileum. Comp Biochem Physiol 71:477-479

26. Avissar NE, Ziegler TR, Toia L, Gu L, Ray EC, BerlangaAcosta J, Sax HC (2004) ATB0/ASCT2 expression in residual rabbit bowel is decreased after massive enterectomy and is restored by growth hormone treatment. J Nutr 134:21732177

27. Wilmore DW, Lacey JM, Soultanakis RP, Bosch RL, Byrne TA (1997) Factors predicting a successful outcome after pharmacologic bowel compensation. Ann Surg 226:288292

28. Matarese LE, Seidner DL, Steiger E (2004) Growth hormone, glutamine, and modified diet for intestinal adaptation. J Am Diet Assoc 104:1265-1272 
29. Sukhotnik I, Shiloni E, Mogilner J, Lurie M, Hirsh M, Coran AG., M.M Krausz (2005) Effect of gender and sex hormones on structural intestinal adaptation following massive small bowel resection in rat. J Pediatr Surg 40:489-495

30. Drucker DJ (2002) Gut adaptation and the glucagon-like peptides. Gut 50:428-435

31. Litvak DA, Hellmich MR, Evers BM, Banker NA, Townsend CM Jr (1998) Glucagon-like peptide 2 is a potent growth factor for small intestine and colon. J Gastrointest Surg 2:146-150

32. Martin GR, Wallace LE, Hartmann B, Holst JJ, Demchyshyn L, Toney K, Sigalet DL: Nutrient stimulated GLP-2 release and crypt cell proliferation in experimental short bowel syndrome. Am J Physiol Gastrointest Liver Physiol (in press)

33. Uluutku AH, Akin ML, Kurt Y, Yucel E, Cermik H, Avsar K, Celenk T (2004) Bombesin in short bowel syndrome. J Invest Surg 17:135-141

34. Sukhotnik I, Khateeb K, Krausz MM, Sabo E, Siplovich L, Coran AG, Shiloni E (2002) Sandostatin impairs postresection intestinal adaptation in a rat model of short bowel syndrome. Dig Dis Sci 47:2095-2102

35. Sukhotnik I, Yakirevich E, Coran AG, L.Siplovich, Hirsh M, Sabo E, Krausz M, Shiloni E (2002) Effect of transforming growth factor-alpha on intestinal adaptation in a rat model of short bowel syndrome. J Surg Res 108:235-242

36. Lund PK (1994) Insulin-like growth factors. In: Dockray G, Walsh JH (eds) Gut peptides: biochemistry and physiology. Raven, New York

37. Lund PK (1998) Molecular basis of intestinal adaptation: the role of the insulin-like growth factor system. Ann N Y Acad Sci 859:18-36

38. Lund PK, Moats-Staats BM, Hynes MA, Simmons JG, Jansen M, D'Ercole AJ, Van Wyk JJ (1986) Somatomedin-C/insulinlike growth factor-I and insulin-like growth factor-II mRNAs in rat fetal and adult tissues. J Biol Chem 261:14539-14544

39. Han VK, Lund PK, Lee DC, D'Ercole AJ (1988) Expression of somatomedin/insulin-like growth factor messenger ribonucleic acids in the human fetus: identification, characterization, and tissue distribution. J Clin Endocrinol Metab 66:422-429

40. Ziegler TR, Mantell MP, Chow JC, Rombeau JL, Smith RJ (1996) Gut adaptation and the insulin-like growth factor system: regulation by glutamine and IGF-1 administration. Am J Physiol 271:G866-G875

41. Vanderhoof JA, McCusker RH, Clark R, Mohammadpour H, Blackwood DJ, Harty RF, Park JH (1992) Truncated and native insulinlike growth factor I enhance mucosal adaptation after jejunoileal resection. Gastroenterology 102:1949-1956

42. Sukhotnik I, Mogilner J, Shamir R, Shehadeh N, Bejar J, Hirsh M, Coran AG (2005) Effect of subcutaneous insulin on intestinal adaptation in a rat model of short bowel syndrome. Pediatr Surg Int 21: 132-137

43. Yang H, Antony PA, Wildhaber BE, Teitelbaum DH (2004) Intestinal intraepithelial lymphocyte gamma delta-T cell-derived keratinocyte growth factor modulates epithelial growth in the mouse. J Immunol 172:4151-4158

44. Asensio AB, Garcia-Urkia N, Aldazabal P, Bachiller P, GarciaArenzana JM, Eizaguirre I (2003) Incidence of bacterial translocation in four different models of experimental short bowel syndrome. Cir Pediatr 16:20-25

45. O'Brien DP, Nelson LA, Kemp CJ (2002) Intestinal permeability and bacterial translocation are uncoupled after small bowel resection. J Pediatr Surg 37:390-394

46. Wildhaber BE, Yang H, Coran AG, Teitelbaum DH (2003) Gene alteration of intestinal intraepithelial lymphocytes in response to massive small bowel resection. Pediatr Surg Int 19:310-315

47. Sukhotnik I, Krausz MM, Sabo E, Resnick M, Hirsh M, Mannheim D, Shiloni E (2003) Endotoxemia inhibits intestinal adaptation in a rat model of short bowel syndrome. Shock 19:66-70

48. Forchielli ML, Walker WA (2003) Nutritional factors contributing to the development of cholestasis during total parenteral nutrition. Adv Pediatr 50:245-267

49. Quiros-Tejeira RE, Ament ME, Reyen L, Herzog F, Merjanian M, Olivares-Serrano N, Vargas JH (2004) Long-term parenteral nutritional support and intestinal adaptation in children with short bowel syndrome: a 25-year experience. J Pediatr 145:157-163

50. Weber TR, Keller MS (2002) Adverse effects of liver dysfunction and portal hypertension on intestinal adaptation in short bowel syndrome in children. Am J Surg 184:582-586

51. Lillehei RC, Manax WG, Lyons GW, Dietzman RH (1966) Transplantation of gastrointestinal organs, including small intestine and stomach. Gastroenterology 51:936-948

52. Atalay F, Ozcay N, Gundogdu H, Orug T, Gungor A, Akoglu M (2003) Evaluation of the outcomes of short bowel syndrome and indications for intestinal transplantation. Transplant Proc 35:3054-3056

53. Grikscheit TC, Siddique A, Ochoa ER, Srinivasan A, Alsberg E, Hodin RA, Vacanti JP (2004) Tissue-engineered small intestine improves recovery after massive small bowel resection. Ann Surg 240:748-754

54. Gunsar C, Vatansever HS, Arslan OA, Sencan A, Muftuoglu S, Ozbilgin K, Kaymaz F, Mir E (2004) The maturity of intestinal neomucosa: integrin expression and ultrastructural aspects. J Pediatr Surg 39:1368-1375

55. Wang ZQ, Watanabe Y, Toki A (2003) Experimental assessment of small intestinal submucosa as a small bowel graft in a rat model. Pediatr Surg 38:1596-1601

56. McDoniel K, Taylor B, Huey W, Eiden K, Everett S, Fleshman J, Buchman TG, Alpers D, Klein S (2004) Use of clonidine to decrease intestinal fluid losses in patients with high-output short-bowel syndrome. J Parenter Enteral Nutr 28:265-268

57. Kato J, Sakamoto J, Teramukai S, Kojima H, Nakao A (2004) A prospective within-patient comparison clinical trial on the effect of parenteral cimetidine for improvement of fluid secretion and electrolyte balance in patients with short bowel syndrome. Hepatogastroenterology 51:1742-1746

58. Seguy D, Vahedi K, Kapel N, Souberbielle JC, Messing B (2003) Low-dose growth hormone in adult home parenteral nutrition-dependent short bowel syndrome patients: a positive study. Gastroenterology 124:293-302 